\title{
Low-Level Laser Therapy: Potential and Complications
}

\author{
Babak Arjmand $^{1}{ }^{\circledR}$, Mahmood Khodadost ${ }^{2}$, Somayeh Jahani Sherafat ${ }^{3}$, Mostafa Rezaei Tavirani ${ }^{* *}$ \\ , Nayebali Ahmadi ${ }^{4}$, Maryam Hamzeloo Moghadam ${ }^{5}$, Farshad Okhovatian ${ }^{6}$, Sina Rezaei Tavirani', \\ Mohammad Rostami-Nejad ${ }^{8}{ }^{\circledR}$
}

${ }^{1}$ Cell Therapy and Regenerative Medicine Research Center, Endocrinology and Metabolism Molecular-Cellular Sciences Institute, Tehran University of Medical Sciences, Tehran, Iran

${ }^{2}$ School of Traditional Medicine, Shahid Beheshti University of Medical Sciences, Tehran, Iran

${ }^{3}$ Laser Application in Medical Sciences Research Center, Shahid Beheshti University of Medical Sciences, Tehran, Iran

${ }^{4}$ Proteomics research center, Faculty of Paramedical Sciences, Shahid Beheshti University of Medical Sciences, Tehran, Iran

${ }^{5}$ Traditional Medicine and Materia Medica Research Center, School of Traditional Medicine, Shahid Beheshti University of Medical Sciences, Tehran, Iran

${ }^{6}$ Physiotherapy Research Centre, Shahid Beheshti University of Medical Sciences, Tehran, Iran ${ }^{7}$ Proteomics research center, Shahid Beheshti University of Medical Sciences, Tehran, Iran

${ }^{8}$ Gastroenterology and Liver Diseases Research Center, Research Institute for Gastroenterology and Liver Diseases, Shahid Beheshti University of Medical Sciences, Tehran, Iran

*Correspondence to Mostafa Rezaei Tavirani, Proteomics Research Center Faculty of Paramedical Sciences, Shahid Beheshti University of Medical Sciences, Tehran, Iran. Email: tavirany@yahoo.com

Received: May 11, 2021 Accepted: July 3, 2021 Published online August 4, 2021

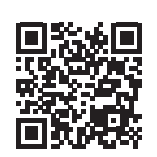

\section{Introduction}

Laser (light amplification by stimulated emission of radiation) as a new concept emerged from research by Einstein in 1917 on the physical principles of stimulated light emission. ${ }^{1}$ On the other hand, achieving a minimally invasive technique for the treatment of different pathologic processes was continually a challenge throughout the world. Recent advances have introduced laser therapy as an applicable treatment, which can be used in various kinds of medical sciences such as pain reduction, inflammation, as well as accelerating the process of tissue repairment., ${ }^{2,3}$ In addition to their practical usefulness in the operating room, lasers have a wide range of applications in ophthalmology, lithotripsy, the diagnosis and treatment of various cancers, as well as dermatologic and cosmetic procedures. ${ }^{4}$ The main part of laser therapy, known as low-level laser therapy (LLLT), through photoactivating cellular mechanisms, promotes a reduction in edema and the induction of analgesia as well as an acceleration of the tissue repair process. This mode of laser therapy has both inhibitory and excitatory effects. ${ }^{5,6}$ Nevertheless, the main effects of lasers on decreasing pain and repairing tissue have not been completely understood. ${ }^{7}$ In the present study, it is attempted to elucidate the benefits and possible disadvantages of laser therapy in the clinical fields. 


\section{Methods}

A combination of laser therapy and regenerative medicine, cosmetic, dentistry, neurodegenerative diseases, kidney, bone fracture, and vaginal function in the English language in the range of 2000-2021 were searched through google scholar. After title screening, the abstracts were evaluated to access the related full texts. The appreciated articles were included in this review article.

\section{Basic Concepts of Laser Therapy}

Different types of laser light devices produce intense, coherent, monochromatic, and highly collimated beam of light. ${ }^{8}$ Recent studies have shown that the best wavelength in laser therapy involves visible red and nearinfrared (NIR) portions of the electromagnetic spectrum (390-1600 $\mathrm{nm}$ and $10^{13}-10^{15} \mathrm{~Hz}$ ) because these portions of the spectrum have been absorbed highly by the biological systems. ${ }^{9}$ Laser treatment induces low energy density, but it is high enough to stimulate the membrane or organelles of the targeted cell. Chromophores, which absorb photons, exist mainly in tissues like hemoglobin and melanin and their highest absorption band is during shorter waves. On the other hand, infrared photons with shorter waves can be absorbed by water. As a result, low-level lasers are known as suitable tools in medicine. Low-level lasers such as Krypton, Argon, $\mathrm{He}, \mathrm{Ne}$, and ruby are kinds of lasers affecting biological systems through non-thermal means. ${ }^{10}$ When the tissue chromophores are affected by laser energy, the cytochromes in the mitochondria absorb the laser radiation and convert them into energy by the cell (ATP), and produced energy causes protein synthesis and acceleration or stimulation of cell proliferation. ${ }^{1,11}$ Different parameters affect the interaction of light and biological tissues such as wavelength, laser dose, and the optical properties of the tissue. The tissue properties include its structure, water content, thermal conductivity, heat capacity, density, and ability to absorb, scatter, or reflect the emitted energy. ${ }^{12}$ The resolution list of further lasers which are used in medicine is presented in Table $1 .{ }^{11}$

\section{Regenerative Medicine and Laser Therapy}

It is reported that the mitochondrial respiratory chain is a suitable chromophore for red to near-infrared light. It can be concluded that mitochondria are appropriate targets in laser therapy (photo biomodulation therapy). It is a well-known fact that mitochondria are the important organelles of the cells which contain critical biomolecules such as reactive oxygen species (ROS), nitric oxide (NO), adenosine triphosphate (ATP), and cyclic adenosine monophosphate (cAMP). It is proposed that laser therapy affects the production of these biomolecules, which is accompanied by the initiation of cell proliferation. This, in turn, induces the signal cascade effects. ${ }^{13,14}$ Recently, researchers have published findings of the role of LLLT in the prevention of endothelial dysfunction development in COVID-19 patients. Based on these investigations, the clinical experience of the treatment and rehabilitation of COVID-19 patients is affected by LLLT. ${ }^{15}$

\section{Cosmetic Applications of Laser Therapy and Complications}

Cosmetic application of laser therapy is a well-known field of laser therapy which has attracted a great deal of attention in dermatology and related fields. ${ }^{16}$ Various parameters of an applied laser should be optimized to achieve a suitable therapeutic tool. Laser wavelength and pulse duration are the two important properties in laser therapy. It is reported that there are associated complications with laser therapy, such as burns, infections, dyspigmentation, ophthalmic injuries, Koebner phenomenon, scarring, prolonged erythema, acne, milia, and contact dermatitis. Therefore, it should be considered that the prevention of these effects need precautions to decrease long-term consequences. ${ }^{17}$

\section{Application of Laser Therapy in Dentistry}

It should be mentioned that the popularity of laser applications in dentistry is tied to the 1990s. it is known that a laser is a therapeutic or adjunct tool in dentistry. ${ }^{18}$ The application of laser irradiation in dentistry has established for various kinds of purposes. The effect of laser application in several aspects of dentistry such as root canal disinfections and pain reduction following orthodontic elastomeric separation has been investigated

Table 1. List of Popular Applied Lasers in Medicine ${ }^{11}$

\begin{tabular}{|c|c|}
\hline Applied Filed & Laser Type and Related Wavelength \\
\hline Dermatology & $\begin{array}{l}\text { Ruby }(694 \mathrm{~nm}) \\
\text { KTP }(532 \mathrm{~nm}) \\
\text { XeCl Excimer }(308 \mathrm{~nm}) \\
\text { Nitrogen }(337 \mathrm{~nm}) \\
\text { Cooper vapor }(578 \mathrm{~nm}) \\
\text { Flash lamp pumped dye }(580-600 \mathrm{~nm}) \\
\text { Argon }(350-514)\end{array}$ \\
\hline Photodynamic therapy & $\begin{array}{l}\text { HeNe (633) } \\
\text { Gold vapor (628) } \\
\text { Argon pumped dye (630-690) } \\
\text { KTP pumped dye (580-600) } \\
\text { Argon (350-514) } \\
\text { Diode lasers (630-980) }\end{array}$ \\
\hline Surgery & $\begin{array}{l}\text { Argon (350-514) } \\
\text { CO2 (10600) } \\
\text { Diode lasers }(630-980) \\
\text { Er: YAG }(2940) \\
\text { Ho: YAG }(2130)\end{array}$ \\
\hline Corneal surgery & $\operatorname{ArF}(193)$ \\
\hline Bone cutting & Alexandrite (720-800) \\
\hline Dentistry & $\begin{array}{l}\text { Er: YAG }(2940) \\
\text { Ho: YAG }(2130)\end{array}$ \\
\hline Wide application & Nd: YAG (1064) \\
\hline
\end{tabular}


and confirmed by researchers. ${ }^{19,20}$ It is reported that the two popular uses of laser therapy are the stimulation of the healing process and pain relief. ${ }^{21}$ The potential of a laser as an alternative method to conventional methods in medicine, in detecting and removal of caries lesions, pulp therapy, dental hypersensitivity, surgery is emphasized by researchers. $^{22}$

\section{Photobiomodulation Therapy and Neurodegenerative Diseases}

There are pieces of evidence that photo biomodulation has a positive effect on neurodegenerative diseases such as Parkinson's disease, Alzheimer's disease, and different types of epilepsy. The findings are characterized by excellent outcomes for animal researches, but they show poor outcomes in clinical studies. It seems that progress in this field requires more investigations. ${ }^{23}$ The cognitive effect of transcranial LLLT on mice is reported by Salehpour et al and Chang et al have investigated the role of transcranial LLLT in depression. ${ }^{24,25}$ It seems this field of investigation will experience more achievements in the near future.

\section{Laser Therapy and Kidney Diseases}

Macagnan and colleagues' investigation indicates that PBMT improves maximal handgrip strength in chronic kidney disease patients who present muscle weakness, fatigue, and reduced functional performance. The samples of research were 15 chronic kidney disease patients who were under treatment for $6 \pm 4$ years. This finding indicates that PBMT can improve the kidney disease patients' life quality and ability. ${ }^{26}$ In another assessment, the importance of the thulium fiber laser in kidney stone treatment is investigated by Traxer and Keller. ${ }^{27}$ Oates et al evaluated the role of the acupuncture laser in pain reduction in pediatric kidney biopsies. ${ }^{28}$

\section{Bone Fracture and Laser Therapy}

Baek et al are reported that; posttraumatic edema is reduced in patients with facial bone fracture which were treated by light-emitting diode-based LLLT. Forty patients that had experienced facial bone fracture were included in this research. ${ }^{29}$

\section{Laser Therapy and Vaginal Function}

Gambacciani and Palacios showed that the fractional CO2 laser and also the non-ablative vaginal Er:YAG laser have an effective role in the morphological change in vaginal tissue. They proposed laser therapy as a treatment tool for stress urinary incontinence. ${ }^{30}$

\section{Conclusion}

It can be concluded that laser therapy has attracted experts' attention in nearly all fields of medicine. As it was mentioned above, there are some complications with laser therapy. Therefore, two important points should be considered to achieve an effective therapeutic method in laser therapy; the first point is the large capacity of a laser for its application in medicine, which implies more attempts to improve its physical and clinical parameters such as light wavelength, duration, fractionation and tissue targets, and the second one is the consideration of its complication to reduce the unfavorable side effects.

\section{Ethical Considerations \\ Not applicable.}

\section{Conflict of Interests}

There is no conflict of interest.

\section{Acknowledgment}

This project is supported by Shahid Beheshti University of Medical Sciences.

\section{References}

1. da Silva JP, da Silva MA, Almeida APF, Junior IL, Matos AP. Laser therapy in the tissue repair process: a literature review. Photomed Laser Surg. 2010;28(1):17-21. doi: 10.1089/pho.2008.2372.

2. Rocha Júnior AM, Vieira BJ, Andrade LCFd, Aarestrup FM. Effects of low-level laser therapy on the progress of wound healing in humans: the contribution of in vitro and in vivo experimental studies. J Vasc Bras. 2007;6(3):257-65. doi: org/10.1590/S1677-54492007000300009

3. Gelape CL. Surgical wound infection following heart surgery. Arq Bras Cardiol. 2007;89(1):3-9. doi: 10.1590/ s0066-782x2007001300013.

4. Azadgoli B, Baker RY. Laser applications in surgery. Ann Transl Med. 2016;4(23):452. doi: 10.21037/atm.2016.11.51.

5. Tumilty S, Munn J, Abbott JH, McDonough S, Hurley DA, Baxter GD. Laser therapy in the treatment of Achilles tendinopathy: a pilot study. Photomed laser surg. 2008;26(1):25-30. doi: 10.1089/pho.2007.2126.

6. Yasukawa A, Hrui H, Koyama Y, Nagai M, Takakuda K. The effect of low reactive-level laser therapy (LLLT) with helium-neon laser on operative wound healing in a rat model. J Vet. Med. Sci. 2007;69(8):799-806. doi: 10.1292/ jvms.69.799.

7. Enwemeka CS, Parker JC, Dowdy DS, Harkness EE, Harkness LE, Woodruff LD. The efficacy of low-power lasers in tissue repair and pain control: a meta-analysis study. Photomed Laser Ther. 2004;22(4):323-9. 10.1089/ pho.2004.22.323.

8. Fonseca AS, Moreira TO, Paixão DL, Farias FM, Guimaraes OR, de Paoli S, et al. Effect of laser therapy on DNA damage. Lasers Surg Med. 2010;42(6):481-8. doi: 10.1002/ 1sm.20921.

9. Hawkins D, Houreld N, Abrahamse H. Low level laser therapy (LLLT) as an effective therapeutic modality for delayed wound healing. Ann NY Acad Sci. 2005;1056(1):48693. doi: 10.1196/annals.1352.040.

10. Lin F, Josephs SF, Alexandrescu DT, Ramos F, Bogin V, Gammill V, et al. Lasers, stem cells, and COPD. J Transl Med. 2010;8(1):1-10. doi.org/10.1186/1479-5876-8-16. 
11. Khalkhal E, Razzaghi M, Rostami-Nejad M, RezaeiTavirani M, Beigvand HH, Tavirani MR. Evaluation of laser effects on the human body after laser therapy. J Lasers Med Scie. 2020;11(1):91-7. doi: 10.15171/jlms.2020.15

12. Knappe V, Frank F, Rohde E. Principles of lasers and biophotonic effects. Photomed Laser Surg. 2004;22(5):4117. doi: 10.1089/pho.2004.22.411.

13. Khorsandi K, Hosseinzadeh R, Abrahamse H, Fekrazad R. Biological responses of stem cells to photobiomodulation therapy. Curr Stem Cell Res Ther. 2020;15(5):400-13. doi: 10.2174/1574888X15666200204123722.

14. Sabino VG, Ginani F, da Silva TN, Cabral AA, MotaFilho HG, Freire MCLC, et al. Laser therapy increases the proliferation of preosteoblastic MC3T3-E1 cells cultured on poly (lactic acid) films. J Tissue Eng Regen Med. 2020;14(12):1792-803. doi: 10.1002/term.3134.

15. Moskvin S, Askhadulin E, Kochetkov A. Low-Level Laser Therapy in Prevention of the Development of Endothelial Dysfunction and Clinical Experience of Treatment and Rehabilitation of COVID-19 Patients. Rehabil Res Pract. 2021;2021:6626932. doi: 10.1155/2021/6626932.

16. Dsouza L, Ghate VM, Lewis SA. Derma rollers in therapy: the transition from cosmetics to transdermal drug delivery. Biomed Microdevices. 2020;22(4):1-11. doi: 10.1007/ s10544-020-00530-3

17. Schwartzberg L, Gold MH. Complications seen with the use of lasers for cosmetic applications. Dermatol Rev. 2020;1(2):63-70. doi.org/10.1002/der2.27

18. Luke AM, Mathew S, Altawash MM, Madan BM. Lasers: A review with their applications in oral medicine. J Lasers Med Sci. 2019;10(4):324-9. doi: 10.15171/jlms.2019.52.

19. Bordea IR, Hanna R, Chiniforush N, Gradinaru E, Campian RS, Sirbu A, et al. Evaluation of the outcome of various laser therapy applications in root canal disinfection: a systematic review. Photodiag Photodyn Ther. 2020;29:101611. doi: 10.1016/j.pdpdt.2019.101611.

20. Almallah MME, Hajeer MY, Almahdi WH, Burhan AS, Latifeh Y, Madkhaneh SK. Assessment of a single versus double application of low-level laser therapy in pain reduction following orthodontic elastomeric separation: a randomized controlled trial. Dent Med Probl. 2020;57(1):45-52. doi: 10.17219/dmp/113332

21. Nadhreen A, Alamoudi N, Elkhodary H. Low-level laser therapy in dentistry: Extra-oral applications. Niger J Clin Pract. 2019;22(10):1313-1318. doi: 10.4103/njcp. njcp_53_19.

22. Marțu MA, Savin C, Kharitos K, Foia L, Forna N. Uses of laser therapy in pediatric dentistry. J Oral Rehabil. 2017;9(2):21-5. doi: 10.4103/ijpr.ijpr_17_18

23. Hong N. Photobiomodulation as a treatment for neurodegenerative disorders: current and future trends. Biomed Eng Lett. 2019;9(3):359-66. doi: 10.1007/s13534019-00115-x

24. Chang J, Wang R, Li C, Wang Y, Chu X-P. Transcranial LowLevel Laser Therapy for Depression and AlzheimerÃđ Â Â s Disease. Neuropsychiatry. 2018;8(2):477-83. doi: 10.4172/ Neuropsychiatry.1000369

25. Salehpour F, Ahmadian N, Rasta SH, Farhoudi M, Karimi P, Sadigh-Eteghad S. Transcranial low-level laser therapy improves brain mitochondrial function and cognitive impairment in D-galactose-induced aging mice. Neurobiol Aging. 2017;58:140-50. doi: 10.1016/j. neurobiolaging.2017.06.025

26. Macagnan FE, Baroni BM, Cristofoli ÉZ, Godoy M, Schardong J, Plentz RDM. Acute effect of photobiomodulation therapy on handgrip strength of chronic kidney disease patients during hemodialysis. Lasers Med Sci. 2019;34(4):835-40. doi: 10.1007/s10103018-2593-7

27. Traxer O, Keller EX. Thulium fiber laser: the new player for kidney stone treatment? A comparison with Holmium: YAG laser. World J Urol. 2020 Aug;38(8):1883-1894. doi: 10.1007/s00345-019-02654-5

28. Oates A, Benedict KA, Sun K, Brakeman PR, Lim J, Kim C. Laser acupuncture reduces pain in pediatric kidney biopsies: a randomized controlled trial. Pain. 2017;158(1):103-9. doi: 10.1097/j.pain.0000000000000734

29. Baek WY, Byun IH, Yun IS, Kim JY, Roh TS, Lew DH, et al. The effect of light-emitting diode (590/830 nm)based low-level laser therapy on posttraumatic edema of facial bone fracture patients. J Craniomaxillofac Surg. 2017;45(1):1875-7. doi: 10.1016/j.jcms.2017.08.027

30. Gambacciani M, Palacios S. Laser therapy for the restoration of vaginal function. Maturitas. 2017;99:10-15. doi: 10.1016/j.maturitas.2017.01.012. 